\title{
WAKAF UANG MENURUT TUAN GURU NAHDLATUL WATHAN DI LOMBOK NUSA TENGGARA BARAT
}

\author{
Anton Priyo Nugroho \\ Dosen FIAI UII Yogyakarta \\ Jl. Kaliurang KM 14 Sleman, Yogyakarta \\ e-mail : anton.kajor@gmail.com \\ Siti Achiria \\ Dosen FIAI UII Yogyakarta \\ Jl. Kaliurang KM 14 Sleman, Yogyakarta \\ M. Arif Muliadi \\ Account Officer, BNI Syariah Kantor Cabang Mataram NTB
}

Jl. Pejanggik No. 33 Cakranegara, Mataram, Kota Mataram, Nusa Tenggara Barat

\begin{abstract}
Abstrak
Nahdlatul Wathan mempunyai peran yang cukup besar dalam pembangunan sosial keagamaan, terutama di daerah Lombok Nusa Tenggara Barat. Peran tersebut tidak dapat dilepaskan dari sosok tuan guru sebagai pemimpin keagamaan Nahdlatul Wathan. Hal ini bukan menisbikan peran pihak lain, namun peran pemimpin agama seperti tuan guru sangat dominan di Lombok. Di sisi lain, wakaf uang berkembang sebagai salah satu persoalan kontemporer umat. Wakaf uang masih dianggap sebagai fenomena baru dikalangan umat Islam di Indonesia, sehingga masih terdapat silang pendapat diantara pemimpin agama. Pandangan tuan guru, terhadap wakaf uang sangat penting agar wakaf uang berkembang dengan baik. Oleh karena itu penelitian ini bertujuan untuk mengetahui pendapat tuan guru mengenai wakaf uang. Penelitian ini menggunakan pendekatan kualitatif, dan menggunakan metode wawancara terhadap 10 orang tuan guru Nahdhatul Wathan di Lombok NTB. Penelitian ini menemukan bahwa sebagian besar tuan guru membolehkan wakaf uang dengan pertimbangan bahwa manfaat lebih besar dibandingkan mudaratnya. Hanya sebagian kecil tuan guru yang melarang wakaf uang karena wakaf harus bersifat tetap, tidak berubah dan tidak boleh berkurang.
\end{abstract}

Kata kunci : hukum Islam, wakaf, wakaf uang, tuan guru, Lombok

\begin{abstract}
Nahdlatul Wathan has a significant role in religious social development, especially in the Lombok area of West Nusa Tenggara (NTB). The role cannot be separated from the tuan guru as religious leaders of Nahdlatul Wathan. This is not to deny the other party's role, but the role of religious leader like tuan guru is very dominant in Lombok. On the other hand, cash waqf develops as one of the contemporary issues of the ummah. Cash waqf is still considered a new phenomenon among Muslims in Indonesia, so there are still differences of opinion between religious leaders. Tuan guru's view on cash waqf is very important in order for cash waqfo develop well. Therefore this study aims to know the opinion of the tuan guru about cash waqf. This study used a qualitative approach, and it
\end{abstract}




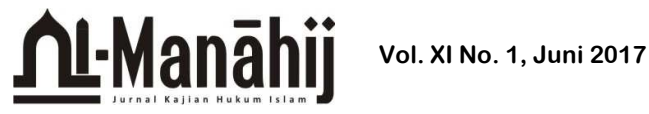

used interview method to 10 tuan gurus of Nahdhatul Wathan in Lombok NTB. The study found that most of tuan guru allowed the cash waqf with the consideration that the benefits were greater than the harm. Only a small proportion of tuan guruforbid cash waqf because waqf should be fixed, unchanged and should not be reduced.

Keywords: Islamic law, waqf, cash waqf, tuan guru, Lombok

\section{A. Pendahuluan}

Nahdlatul Wathan adalah sebuah organisasi sosial kemasyarakatan dengan fokus kegiatan pada bidang pendidikan, sosial dan dakwah keagamaan, merupakan organisasi tertua dan terbesar di Nusa Tenggara Barat. Organisasi Nahdlatul Wathan (NW) ini didirikan pada tanggal 1 Maret 1953 di Pancor Lombok Timur Nusa Tenggara Barat (NTB), oleh seorang ulama besar yaitu Maulana Syekh TGKH. M. Zainuddin Abdul Majid. ${ }^{1}$ Nahdhatul Wathan pada beberapa sisi, memiliki persamaan dengan Nahdlatul Ulama dilihat dari akidah, fikih, tasawuf, yaitu sejalan dengan pemikiran imam mazhab Syafii, akan tetapi dalam hal tarekat, Nahdlatul Ulama lebih dominan kepada tarekat Qadiriyah wan Naqsabandiyah sedangkan Nahdlatul Wathan mempunyai tarekat tersendiri yang dibuat oleh pendirinya yaitu Maulana Syaeh TGKH. M. Zainuddin Abdul Majid dengan nama Tariqah Hizib Nahdlatul Wathan. Berbeda dengan Muhammadiyah dalam hal syariah atau fikih, Muhammadiyah langsung berpatokan kepada al-Qur'an, Hadis dan tarjih (memilih pendapat terkuat) dan mengikuti faham salaf serta tasawuf modern, yang lebih menekankan pembaharuan Islam modern dalam penetapan hukum dan ajarannya.

$$
\text { Nahdlatul Wathan sebagai }
$$

organisasi Islam yang memusatkan perjuangannya dalam bidang pendidikan, sosial dan dakwah Islamiah mengalami perkembangan yang cukup besar, dalam kaitannya dengan pembangunan sosial keagamaan, tidak terlepas dari peran tuan guru yang menjadi sosok pemimpin. Hal ini sejalan dengan pendapat yang dikemukakan oleh Arie, bahwa tuan guru cukup potensial untuk turut menggerakkan masyarakat secara umum, sebab bagaimanapun keberadaan tuan guru sebagai elit sosial dan agama menempati posisi dan peran sentral dalam struktur sosial masyarakat Lombok. ${ }^{2}$

Di sisi lain, persoalan agama yang semakin dinamis pada masyarakat Lombok adalah wakaf. Wakaf yang pada awalnya hanya berupa wakaf tanah, gedung dan aset-aset tetap lainnya telah berkembang keberbagai bentuk, salah satunya adalah wakaf uang. Wakaf uangsangat potensial untuk dikembangkan menjadi wakaf produktif, yaitu dengan melakukan proses transformasi faktor-faktor produksi secara syar' $i$, dengan input utama aset wakaf, untuk menciptakan nilai tambah atau menghasilkan profit bagi kepentingan sosial ${ }^{3}$.Akan tetapi realitanya, dana wakaf uang yang terkumpul belum maksimal.Menurut data laporan nadzir Badan Wakaf Indonesia (BWI) per 20 Desember 2011, dana yang berhasil dihimpun oleh BWI sebesar Rp.2.973.393.876,- atau kisaran $\mathrm{Rp} \quad 2,97$ milyar. ${ }^{4}$ Salah satu faktor yang menjadi penghambat penghimpunan dana wakaf uang adalahminimnya pengetahuan dan kefahaman masyarakat muslim terhadap wakaf uang.Hal tersebut sebagaimana diungkapkan Nasution ${ }^{5}$ yang menyatakan bahwa kurang fahamnya masyarakat 
akan hakikat serta makna wakaf mengakibatkan masih sedikitnya anggota masyarakat yang mau berpartisipasi dalam berwakaf uang, dan hal ini pula yang terjadi di Lombok.

Nahdlatul Wathan yang dipimpin oleh tuan guru, sangat potensial untuk mempengaruhi persepsi dan membantu pemahaman masyarakat dalam memahami wakaf uang sehingga akan membawa dampak positif bagi perkembangan pengetahuan masyarakat tentang wakaf uang di Lombok. Dalam halinterpretasi dan pelaksanaan hukum keagamaan, tuan guru memiliki posisi dan peran sentral di masyarakat Lombok, serta memiliki pengaruh yang kuat dalam membentuk dan membentuk kembali (shape and reshape) cara pandang masyarakat, ke arah mana interpretasi aturan normatif agama dilaksanakan. ${ }^{6}$ Dengan demikian pandangan tuan guru terhadap wakaf uang, akan berpengaruh terhadap cara pandang masyarakat lombok pada umumnya.

Namun demikian ada beberapa persoalan yang muncul berkaitan dengan wakaf uang ini, pertama, aktivitas ijtihad dan fatwa keislaman tidak banyak terdengar dari tuan guru Nahdlatul Wathan, dengan perkataan lain, tidak pernah tersiar berita tentang adanya suatu pemikiran atau pandangan keislaman kontemporer, sehingga mendorong para peneliti untuk segera menyelenggarakan penelitian tentang diskursus intelektual islam tentang tuan guru Nahdlatul Wathan dan wakaf uang. Hal ini berbeda dengan Lembaga bahtsul masail dalam Nahdlatul Ulama atau lembaga tarjih dalam Muhammadiyah yang kerap memunculkan pandangan keislaman yang diberitakan secara luas. Kedua, berdasar UU No. 41 Tahun 2004 tentang wakaf, maka pada hakikatnya umat Islam di Indonesia telah memiliki pijakan dalam hal wakaf uang, namun dalam realitasnya tidak semua ketentuan-ketentuan hukum Islam yang ditetapkan pemerintah secara mutlak diikuti dan dilaksanakan oleh umat islam, tidak terkecuali para tuan guru Nahdlatul Wathan di Lombok.

Mengingat pentingnya peran tuan guru dalam kehidupan masyarakat Lombok, maka peneliti tertarik untuk melakukan penelitian tentang wakaf uang dalam pandangan tuan guruNahdlatul Wathan, sehingga nantinya wakaf uang di Lombok diharapkan akan semakin meningkat, produktif dan profesional.

\section{B. Pengetahuan Tuan Guru Nahdlatul Wathan tentang Wakaf Uang}

Tuan Guru merupakan anggota dari ormas Islam terbesar di Lombok yaitu Nahdlatul Wathan. Nahdlatul Wathan berasal dari dua kata "nahdah" dan "al-watan". Nahdah berarti kebangkitan, pergerakan, pembangunan, dan al-watan berarti tanah air atau negara, jadi Nahdlatul Wathan adalah kebangkitan tanah air, pembangunan negara atau membangun negara. Secara terminologis Nahdlatul Wathan adalah organisasi Islam Ahlusunah Waljamaah. ${ }^{7}$ Nahdlatul Wathan sebagai organisasi kemasyarakatan melaksanakan segala amal usaha sesuai dengan asas organisasi. Sedangkan sebagai organisasi keagamaan, NW menganut dan menerapkan syariat Islam sesuai akidahnya. Asas dan akidah organisasi merupakan landasan perjuangan organisasi dalam mencapai tujuannya. ${ }^{8}$

Sama seperti sebagian besar ormas Islam, NW menganut mazhab Ahlusunah Waljamaah walaupun pada beberapa sisi ormas-ormas juga memiliki perbedaan, baik itu dalam hal akidah, fikih (syariah) atau tasawuf. Secara ringkas perbedaan antara Nahdlatul Wathan, Muhammadiyah dan Nahdlatul Ulama (NU) dapat dilihat 


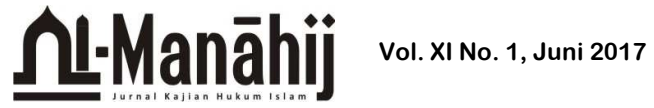

pada tabel 1 di bawah ini: ${ }^{9}$

Tabel 1

Perbedaan Pemikiran Nahdlatul Wathan, Muhammadiyah dan Nahdlatul Ulama

\begin{tabular}{|c|c|c|c|}
\hline Aspek & Nahdlatul Wathan & Muhammadiyah & Nahdlatul Ulama \\
\hline Akidah & $\begin{array}{c}\text { Mengikuti faham } \\
\text { Asy'ariyyah/Maturidiyyah }\end{array}$ & $\begin{array}{l}\text { Mengikuti paham } \\
\text { salaf (Ibn Taimiyah, } \\
\text { Muhammad ibn } \\
\text { Abdul Wahab, Ibn } \\
\text { Qayyim) }\end{array}$ & $\begin{array}{c}\text { Mengikuti faham } \\
\text { Asy'ariah/Maturidiah }\end{array}$ \\
\hline Fikih & $\begin{array}{l}\text { Mengikuti mazhab Syafii } \\
\text { yaitu hukum-hukum Islam } \\
\text { yang digali langsung dari } \\
\text { al-Qur'an dan Hadis oleh } \\
\text { Imam asy-Syāfi'i. }\end{array}$ & $\begin{array}{l}\text { Langsung kepada al- } \\
\text { Qur'an dan Sunah, } \\
\text { dan tarjih (memilih } \\
\text { pendapat yang } \\
\text { terkuat) }\end{array}$ & $\begin{array}{c}\text { Keharusan mengikut } \\
\text { salah satu madzhab } \\
\text { (terutama mazhab } \\
\text { Syafii) }\end{array}$ \\
\hline $\begin{array}{l}\text { Tasawuf/ } \\
\text { Tariqat }\end{array}$ & $\begin{array}{l}\text { Menerima tasawuf, dan } \\
\text { tarekat yang muktabar } \\
\text { seperti tasawuf imam } \\
\text { Junaidal-Bagdadi (diakui) } \\
\text { memiliki tarekat tersendiri } \\
\text { yaitu Tarekat Hizib } \\
\text { Nahdlatul Wathan }\end{array}$ & $\begin{array}{c}\text { Menolak tasawuf dan } \\
\text { tarikat tetapi banyak } \\
\text { yang apresiatif secara } \\
\text { individual dan } \\
\text { selektif, misal Hamka } \\
\text { dengan tasawuf } \\
\text { modernnya }\end{array}$ & $\begin{array}{l}\text { Menerima tasawuf, } \\
\text { dan tarekat yang } \\
\text { muktabar (diakui), } \\
\text { Lebih dominan } \\
\text { mengikuti tarekat } \\
\text { Qadiriah wan } \\
\text { Naqsabandiyah }\end{array}$ \\
\hline $\begin{array}{l}\text { Pemikiran } \\
\text { yang } \\
\text { Dominan }\end{array}$ & $\begin{array}{l}\text { Imam Abu al-Hasan 'Ali } \\
\text { al-Asy'ari, Imam Abu } \\
\text { Mansur al-Maturidi, dll }\end{array}$ & $\begin{array}{c}\text { Ibn Taimiyyah, } \\
\text { Muhammadibn'Abdul } \\
\text { Wahab, Ibn Qayyim, } \\
\text { Muh.Abduh, Rasyid } \\
\text { Ridha }\end{array}$ & $\begin{array}{l}\text { Pemikir klasik : al- } \\
\text { Asy'ari, al-Gazali, } \\
\text { an-Nawawi, dll }\end{array}$ \\
\hline
\end{tabular}

Dari tabel 1 di atas dapat disimpulkan bahwa NW dan NU memiliki persamaan yang cukup mendasar dari akidah, fikih, dan tasawuf yang hampir sama, dengan pemikiran klasik Imam mazhab terutama Imam asy-Syāfi'i, berbeda dengan Muhammadiyah yang lebih menekankan pembaharuan islam modern dalam penetapan hukum dan ajarannya. Melihat beberapa perbedaan-perbedaan tersebut diatas, maka sangat mungkin terjadi perbedaan-perbedaan pemikiran tentang wakaf uang dikalangan ulama Nahdlatul Wathan. berikut ini:

Profil tuan guru yang menjadi subyek penelitian dapat dilihat seperti tabel 2

Tabel 2

Identitas Responden Berdasarkan Usia, Pendidikan Terakhir, dan Jabatan di Nahdlatul Wathan

\begin{tabular}{cccll}
\hline No & $\begin{array}{c}\text { Kode } \\
\text { Subyek }\end{array}$ & $\begin{array}{c}\text { Usia } \\
(\text { tahun) }\end{array}$ & Pendidikan Terakhir & Jabatan di NW saat ini \\
\hline 1 & MYM & 64 & As-Shalatiyah & Amidul MDQH Pancor,
\end{tabular}




\begin{tabular}{|c|c|c|c|c|}
\hline & & & Makkah & 1999-Sekarang \\
\hline 2 & MAR & 62 & $\begin{array}{l}\text { As-Shalatiyah } \\
\text { Makkah }\end{array}$ & $\begin{array}{l}\text { Masyaikh Amidul MDQH Pancor, } \\
\text { 2001-Sekarang }\end{array}$ \\
\hline 3 & SLJ & 44 & $\begin{array}{l}\text { S3 Kajian Studi Islam } \\
\text { IAIN Sunan Ampel }\end{array}$ & $\begin{array}{l}\text { Wakil Katibul'Am Dewan } \\
\text { Mukhtasyar NW, Dosen IAIH dan }\end{array}$ \\
\hline 4 & MAG & 65 & $\begin{array}{l}\text { S1 UIN Sunan } \\
\text { Kalijaga Yogyakarta }\end{array}$ & $\begin{array}{l}\text { Masayaikh Ma'had Darul Qur'an } \\
\text { Wal Hadits 1989-sekarang }\end{array}$ \\
\hline 5 & MZA & 50 & $\begin{array}{l}\text { S2 Darul Ulum } \\
\text { Jombang }\end{array}$ & \multirow{2}{*}{$\begin{array}{l}\text { Dosen IAIH dan Masayaikh } \\
\text { Ketua PBNW Majlis NW, } \\
\text { SEKDA Dewan Masyaikh MDQH }\end{array}$} \\
\hline 6 & LHS & 67 & $\begin{array}{l}\text { Ma'had Darul Qur'an } \\
\text { Wal Hadits }\end{array}$ & \\
\hline 7 & MAI & 41 & $\begin{array}{l}\text { As-Shalatiyah } \\
\text { Makkah }\end{array}$ & $\begin{array}{l}\text { Masyaikh Ma'had Darul Qur'an } \\
\text { Wal Hadits }\end{array}$ \\
\hline 8 & MSR & 59 & S1 STIS Hamzanwadi & Masyaikh Ma'had Darul Qur'an \\
\hline 9 & HPN & 41 & IAIH NW Pancor & Masyaikh Ma'had Darul Qur'an \\
\hline 10 & MSG & 45 & $\begin{array}{l}\text { S3 Universitas Al- } \\
\text { Azhar, Kairo, Mesir }\end{array}$ & $\begin{array}{l}\text { Ketua Yayasan Pendidikan } \\
\text { Hamzanwadi NW Gelogor, Dosen }\end{array}$ \\
\hline
\end{tabular}

Dari hasil wawancara, peneliti menemukan sebagian besar tuan guru Nahdlatul Wathan, mengetahui tentang wakaf uang, namun masih ada sebagian tuan guru yang mengkaitkan wakaf uang dengan wakaf tanah dan ada juga yang masih kurang pemahamannya tentang pengertian wakaf uang itu sendiri.

Wakaf dalam bahasa Arab berarti menahan atau larangan. Menurut Monzer Kahf, kata wakaf yang digunakan dalam islam berarti menahan property tertentu dan melestarikannya untuk digunakan sesuai tujuan yang terbatas serta melarang penggunaan diluar tujuan yang telah ditentukan. ${ }^{10}$ Wakaf uang menurut Shahedur dkk. (2011), wakaf yang berbentuk uang untuk mendukung kegiatan kemanusiaan dengan nama Allah SWT, dana tersebut dapat disalurkan untuk investasi dan hasil investasi dapat digunakan untuk keperluan agama dan sosial. ${ }^{11}$

Sebagian besar subyek ketika memberi pengertian tentang wakaf uang hampir sempurna dengan pengertian wakaf uang pada umumnya, berikut ungkapan Subyek SLJ "Menurut yang saya fahami adalah wakaf yang bentuk objeknya itu adalah uang"(W3:78-79). Subyek MAG "wakaf uang itu adalah penyerahan wakaf berupa barang yang bergerak atau uang kepada suatu orang tau suatu lembaga untuk mengelolany"(W4:297-299).

Dalam ungkapan lain, ada subyek yang berpandangan bahwa wakaf uang dengan wakaf tanah itu sama, akan tetapi wakaf uang harus lebih diproduktifkan karena objeknya adalah uang, seperti ungkapan subyek MZA: "Menurut saya sih sebenarnya sama saja dengan wakaf tanah akan tetapi ini kan dalam pengelolaannya harus lebih diproduktifkan soalnya objeknya kan adalah uang"'(W5:374-376). Namun ada juga subyek yang masih kurang pengetahuannya dan kurang menerima tentang adanya wakaf uang seperti yang di ungkapkan subyek MYM : "Wakaf itu kan berbentuk ain dan ainnya tetap, bukan yang habis, tidak berubah seperti 
uang ini “(W1:3-4).

Hasil wawancara diatas dapat disimpulkan bahwa sebagian besar tuan guru Nahdlatul Wathan mengetahui tentang wakaf uang, dapat memaknai wakaf uang dengan benar meskipun belum sempurna, namun masih ada sebagian tuanguru yang mengaitkan wakaf uang dengan wakaf tanah.

\section{Pandangan Hukum Tuan Guru terhadap Hukum Wakaf Uang}

Beberapa tuan guru belum menentukan atau memberikan hukum tentang wakaf uang, seperti yang diungkapkan subyek MYM dan MAR, menurut pandangan beliau pada dasarnya wakaf itu sifatnya tetap, dan dalam penamaan wakaf tersebut (wakaf uang) masih kurang cocok. Apabila wakaf di relasikan dengan uang masih kurang tepat karena sifat uang yang bisa habis, dan berubah, tidak tetap seperti wakaf tanah pada umumnya, berikut ungkapan subyek MYM : "Belum saya kaji, karna kan yang namanya uang itu kan sifatnya habis, berubah, berubah ini kan berputar dan setau saya definisi wakaf itu adalah mewakafkan ain yang tetap, lalu dalam memanfaatkan itu kan barangnya harus tetap, tidak boleh di hibahkan, sehingga itulah prinsip uang, yang namanya uang itu kan,berubah jelas, seperti misalnya kan kita kirim uang, transfer untuk pembelian apa misalnya lewat bank bukan uang yang kita kirim itu"(W1:11-18).

Namun sebagian besar subyek memberikan pandangan tentang kebolehan wakaf uang, seperti yang diungkapkan subyek SLJ, MAG, MZA, LHS, MAI, MSR, HPN, MSG, dengan pertimbangan bahwa uang hanya sebagai subyek atau simbol semata akan tetapi yang lebih penting nilainya, dan selama harta benda wakaf itu tetap, dan hasil serta keuntungannya disalurkan kepada yang membutuhkan, maka boleh-boleh saja dan unsur yang paling penting adalah tujuan wakaf itu sendiri. Seperti yang diungkapkan subyek SLJ berikut ini: "Kalo pemahaman saya ya, uang itu kan sekala objek atau simbol maka dia kemudian bisa saja di wakafkan artinya karna disini kan yang di lihat tergantung pada nilainya dan kesepakatan, katakanlah yang nilainya seratus ribu misalnya di wakafkan, ya nilai seratus ribu itulah yang menjadi objek perwakafannya, sehingga menurut saya ya, tidak ada masalah"(W3:188193). Subyek yang lain, yaitu subyek LHS membolehkan wakaf uang, dengan pertimbangan bahwa dasar hukum wakaf uang sama dengan wakaf tanah, dan yang paling terpenting adalah tujuan wakaf itu sendiri, berikut ungkapan subyek LHS : "Dengan melihat hukum dari wakaf tanah ya boleh-boleh saja, kan ini uangnya tetap kemudian hasilnya itu nanti di putar dan keuntungannya yang di wakafkan yang penting tujuannya untuk masyarakat luas, untuk fakir, miskin dan menolong orang-orang yang tidak punya"(W6 : 459-463.)

Dengan demikian dapat disimpulkan bahwa, dari sepuluh tuan guru yang diteliti, ada 2 (dua) tuan guru yang belum menentukan hukum kebolehan wakaf uang dengan pertimbangan bahwa pada dasarnya wakaf itu sifatnya tetap, tidak boleh berubah ataupun berkurang dan dalam penamaan wakaf uang tersebut, masih kurang cocok, dan apabila disandingkan antara wakaf dengan uang masih kurang tepat karena sifat uang yang bisa habis, dan berubah, tidak tetap seperti wakaf tanah pada umumnya. Sedangkan kedelapan subyek yang lain membolehkan wakaf uang dengan pertimbangan bahwa wakaf bukan hanya dilihat dari objek uangnya saja, akan tetapi lebih secara umum dilihat dari fungsi nilai dan tujuan wakaf itu sendiri. 


\section{Pandangan Tuan Guru Terhadap Penghimpunan Wakaf Uang}

Dalam penghimpunan wakaf uang, sosialisasi wakaf uang merupakan salah satu instrumen yang sangat penting, namun realitanya masih banyak masyarakat yang belum mengetahui tentang wakaf uang. Melihat tingkat sosialisasi wakaf uang yang masih sangat rendah tersebut, peran tuan guru dalam mensosialisasikan wakaf uang sangat dibutuhkan, hal ini berkaitan dengan peran penting tuanguru dalam struktur masyarakat di Lombok NTB. Pandangan tuanguru akan mempengaruhi masyarakat dalam melakukan wakaf yang pada akhirnya akan berdampak terhadap perkembangan wakaf di NTB. Namun hasil wawancara menemukan sebagian besar tuan guru masih belum mensosialisasikan wakaf uang, belum menganjurkan masyarakat untuk wakaf uang sebagaimana yang di ungkapkan subyek MZA. "Belum sih, tapi insallah untuk kedepannya untuk menganjurkan masyarakat, sekaligus sosialisasi tentang wakaf uang ini" (W5:395-396). Ungkapan senada diucapkan oleh subyek LHS, dengan mengatakan "Untuk wakaf uang ini sih belum" (W6;465).

Walaupun demikian dalam hal penghimpunan wakaf uang, beberapa tuan guru menyarankan agar peran lembaga pemerintah seperti Badan Wakaf Indonesia (BWI) lebih dominan untuk menghimpun wakaf uang dibandingkan dengan lembaga-lembaga swasta. Subyek MAG mengatakan "Boleh saja, gak apa-apa, akan tetapi lebih teratur langsung dari pemerintah saja"(W4:330-331). Hampir semua tuan guru sepakat bahwa wakaf uang tidak hanya dihimpun oleh lembaga pemerintah saja, namun semua pihak termasuk lembaga swasta berhak melakukan penghimpunan wakaf uang, seperti yang diungkapkan subyek MSG berikut : "Wakaf uang boleh saja di himpun oleh siapa saja yang penting dilakukan secara profesional dan memahami aturan-aturan dibawah koridor syari'at."(W10:811-813). Selanjutnya subyek LHS juga mengatakan "Boleh saja selama orang atau badan itu konsekuen, jujur, transparan, dan ikhlas, untuk menyalurkan kepada yang berhak, itu ya bisa kenapa tidak" (W6:474-476).

Dengan demikian dapat disimpulkan tuan guru sepakat bahwa penghimpunan wakaf uang sebaiknya dilakukan oleh BWI agar lebih teratur dan maksimal, namun demikian sebagian besar tuan guru juga berpendapat, bahwa wakaf uang tidak hanya merupakan kewajiban BWI atau badan pemerintah saja, namun semua pihak termasuk lembaga swasta juga berhak menghimpun wakaf uang, selama dilakukan secara profesional dan tidak melanggar aturan koridor-koridor syariah.

\section{E. Pandangan Tuan Guru Terhadap Pengelolaan dan Pemanfaatan Wakaf Uang}

Ada

bermacam-macam pandangan tuan guru, dalam hal pengelolaan wakaf uang, seperti untuk investasi atau deposito harta benda wakaf, sebagaimana yang diungkapkan subyek MZA "Dengan jalan mudharabah itu saja, investasilah istilahnya jadinya kerjasama dengan masyarakat agar bagi hasil ntar untungnya yang turun naik dan jangan sampai modalnya habis, harus tetap, dan benar-benar menguntungkan." (W5:416-419). Tidak jauh berbeda dengan ungkapan subyek MSG, menurut ungkapan subyek MAG, "Ya sepanjang itu didepositokan dan dapat memberikan laba, ya gak apa-apa" (W4:344). Dalam hal lain perlunya badan pemerintah yang punya wewenang seperti Badan Wakaf Indonesia, untuk menjaga, mengelola supaya nilai uang yang diwakafkan tetap 
terjaga, dan penyusun setuju dengan subyek MSR, yang mengungkapkan bahwa: "Kita kan punya badan pemerintah, ya bagaimana ntar badan pemerintah ini membuat MOU dengan perbankan syari'ah dalam hal pengelolaan, tida ada unsur melakukan pelencengan disana kan, kemudian disalurkan kepada yang berhak"(W8:650-653)

Secara umum seluruh tuan guru berpendapat bahwa sebaiknya pengelolaan wakaf uang diserahkan kepada lembaga yang berkompeten baik itu BWI maupun lembaga resmi pemerintah lainnya seperti perbankan syari'ah, akan tetapi tidak menutup kemungkinan pengelolaan wakaf uang dikelola oleh orang atau lembaga swasta yang amanah dan kompeten dalam pengelolaan wakaf uang sehingga nilai wakaf uangnya tidak berkurang namun justru bertambah.

Dalam hal pemanfaatan wakaf uang, hampir semua tuan guru memiliki pendapat yang relatif sama. Berikut ungkapan subyek MAR, "Ya untuk pembangunan sosial, tempat ibadah, dan lain-lain, selama agama tidak melarangnya, bisa juga untuk delapan asnaf dalam zakat itu"(W2:153-155). Hal yang samajuga diungkapkan oleh subyek MAI, "Untuk kesejahteraan kaum muslim, sebesar-besarnya untuk kaum muslim yang membutuhkan ya termasuk juga fakir miskin dan lain sebagainya". Secara umum tuan guru sepakat bahwa wakaf uang harus dimanfaatkan untuk mencapai tujuan dan fungsi wakaf, yaitu untuk kebajikan atau kemaslahatan umat, baik itu dibidang sosial, pendidikan, ekonomi, dan bidang lainnya.

Beberapa tuan guru menyampaikan masukan kepada Badan Wakaf Indonesia sebagai lembaga independen yang berwenang mengelola perwakafan di Indonesia, yaitu: a) Perlunya sosialisasi kepada masyarakat tentang wakaf uang; b) Perlunya pendataan yang merata baik itu harta benda wakaf bergerak maupun tidak bergerak (W2:170-171); c) Badan Wakaf Indonesia harus lebih amanah, jujur dan ikhlas dalam menjalankan tugasnya (W6:510-511);dan d) Sumber daya manusia yang ada dilembaga wakaf haruslah profesional, dan berkompeten dibidangnya (W3:271-277) dan (W8:683-688).

\section{F. Penutup}

Berdasar hasil wawancara terhadap sepuluh tuan guru di Lombok NTB, dapat disimpulkan bahwa pertama, sebagian besar tuanguru membolehkan wakaf uang dengan pertimbangan bahwa wakaf uang memiliki tujuan dan manfaat yang lebih besar dibandingkan mudharatnya, dan tidak ada nash atau ayat yang secara tegas melarang objek-objek tertentu untuk diwakafkan. Hanya sebagian kecil tuan guru yang tidak setuju terhadap wakaf uang, dengan alasan bahwa pada dasarnya wakaf itu sifatnya tetap, tidak boleh berubah ataupun berkurang, dan apabila wakaf tersebut menggunakan uang dianggap tidak tepat karena sifat uang yang dapat habis, berubah, dan tidak tetap seperti wakaf tanah pada umumnya. Kedua, pendapat tuan guru berkaitan dengan manajemen wakaf uang, yang meliputi penghimpunan, pengelolaan, dan pemanfaatan adalah melakukan sosialisasi kepada masyarakat tentang wakaf uang, yang harus didukung oleh semua pihak baik dari pemerintah, lembaga-lembaga wakaf, organisasi masyarakat, tokoh masyarakat serta pengelolaannya harus diserahkan kepada lembaga yang berkompeten dan profesional, sehingga dalam pemanfaatannya, disalurkan secara tepat, transparan dan akuntabel.

Implikasi dari penelitian ini diantaranya: 1) Pemerintah perlu melibatkan tuan guru lebih jauh dalam 
melakukan sosialisasi, penghimpunan, pengelolaan, dan pemanfaatan wakaf uang, karena peran dominan tuan guru dalam struktur masyarakat Lombok NTB. Dengan keterlibatan tuan guru diharapkan dapat mewujudkan kesadaran berwakaf yang nantinya dapat meningkatkan kesejahteraan masyarakat Lombok NTB melalui upaya memproduktifkan aset wakaf; 2) Badan Wakaf Indonesia melalui perwakilannya di Provinsi Nusa Tenggara Barat dapat memberikan pendampingan secara

\section{Catatan Akhir:}

${ }^{1}$ Abdul Hayyi Nu'man, Riwayat Hidup dan Perjuangan TGKH. M. Zainuddin Abdul Majid(Pancor: PBNW, 1999), hlm. 139.

${ }^{2}$ Arie Oktara,"Politik Tuan Guru di Nusa Tenggara Barat", Jurnal Ilmu Pemerintahan Volume 8, Nomor 2, Juli 2015, hlm. 81.

${ }^{3}$ Siti Achiria, "Model Wakaf Produktif pada Sektor Jasa Pendidikan di Indonesia", Disertasi tidak diterbitkan(Yogyakarta: UIN Sunan Kalijaga, 2013), hlm. 75.

${ }^{4}$ Badan Wakaf Indonesia,Laporan Wakaf Uang di BWI (2007-2011).

${ }^{5}$ Edwin Mustafa Nasution dan Uswatun Hasanah, Wakaf Uang Inovasi Finansial(Jakarta: PSTTI-UI,2006).

${ }^{6}$ Muslihun, Menuju Wakaf Produktif (Studi Pergeseran dan Perubahan Pemahaman Tuan Guru tentang Wakaf di Lombok, (Semarang: IAIN Walisongo, 2012).

${ }^{7}$ Kerja sama YPH PPD NW Pancor dan DPC PBB Kab. Lombok Timur. Mengenang Al Magfurullahu Maulanasyaikh TuanGuru Kyai Haji Muhammad Zainuddin Abdul Madjid, Pancor, 2004.

${ }^{8}$ Muhammad Zainuddin, "Organisasi Nahdlatul Wathan,” http://zaikenawa.cc., 2009, hlm. 5 .

${ }^{9}$ Muhammad Al-Ja'bary Hafizh, Gerakan Kebangkitan Islam (Harakah Al-Ba'ts Al-Islami)(Solo: Duta Rahmah, 1996), hlm. 63.

${ }^{10}$ Monzer Kahf, Waqf : a Quick

Overview, 2015, hlm.2.

${ }^{11}$ Shahedur Rahaman Chowdury, Moh. Fahmi Bin Ghazali and Mohd. Faisol Ibrahim, "Economic of Cash Waqf Management in Malaysia : A Proposed Cash WaqfModel for terprogram dalam memproduktifkan aset wakaf, mengingat aset wakaf tanah di Lombok NTB cukup besar, bahkan dapat menjadi salah satu percontohan bagi pengembangan wakaf di Indonesia; 3) Penelitian tentang wakaf uang dalam pandangan tuan guru Nahdlatul Wathan ini perlu untuk dikembangkan dan diteliti lebih lanjut, terutama mengenai adanya gagasan mengenai konsep "wakaf bersama" atau "wakaf berjamaah" yang sudah berjalan dalam praktik perwakafan di Lombok NTB.

Practitioners and Future Research", African Journal of Business Management Vol. 5(30), 2011, hlm. 12156.

\section{DAFTAR PUSTAKA}

Achiria, Siti. "Model Wakaf Produktif pada Sektor Jasa Pendidikan di Indonesia", Disertasi tidak diterbitkan. Yogyakarta: UIN Sunan Kalijaga, 2013.

Badan Wakaf Indonesia. "Laporan Wakaf Uang di BWI (20072011)," http://bwi.or.id/index.php/in/dow nloadtask $=$ finish\&, 2012.Diakses 30 Maret 2014

Chowdury, Shahedur Rahaman., Moh. Fahmi Bin Ghazali and Mohd. Faisol Ibrahim. "Economic of Cash Waqf Management in Malaysia: A Proposed Cash WaqfModel for Practitioners and Future Research" dalamAfrican Journal of Business Management Vol. 5(30), 2011.

Fahrurozzi, "Tuan Guru antara Idealis Normatif dengan Realitas Sosial pada Masyarakat Lombok," 9 September 2013, http://www.penelitiankeislamaniainmataram.com/wpcontent/uploads/2013/09/9- 
Fahrurrozi.pdf. Diakses 23 Maret 2014.

Hafizh, Muhammad Al-Ja'bary. Gerakan Kebangkitan Islam (Harakah al-Ba'ts al-Islami), terj. Abu Ayyub Al Anshari. Solo: Duta Rahmah, 1996.

Hartini, A., Azaimi, A., Aslam, M., \& Hanafi, H..The Possible Role of Waqf in Ensuring A Sustainable Malaysian Federal Government Debt. Procedia Economics and Finance, 2015.

Ihsan, H."Waqf Accounting and Management in Indonesian WAQF Institutions The cases of Two Waqf Foundations" dalam Journal of Humanomics, Vol. 27 No. 4, 2011.

Kahf, Monzer. Waqf : a Quick Overview, 2015.

Kementrian Agama RI. Himpunan Peraturan Perundang-Undangan tentang Wakaf. Jakarta: Direktorat Pemberdayaan Wakaf, 2012.

Muslihun. "Menuju wakaf Produktif (Studi Pergeseran dan Perubahan Pemahaman tuan guru tentang Wakaf di Lombok)", Disertasi tidak diterbitkan. Semarang: IAIN Walisongo, 2012.

Nu'man, Abdul Hayyi. Riwayat Hidup dan Perjuangan TGKH. M. Zainuddin Abdul Majid. Pancor: PBNW, 1999.
Nasution, Edwin Mustafa, dan Uswatun Hasanah. PSTTI-UI Wakaf Uang Inovasi Finansial. Jakarta, 2006.

Oktara, Arie."Politik Tuan Guru di Nusa Tenggara Barat". Dalam Jurnal Ilmu Pemerintahan Volume 8, Nomor 2, Juli 2015.

Ridhwan, M., Aziz, A. dan Yusof, M.A. "Examining the Relationship between Level of Income and Appointment of Agent in Collecting Waqf Fund". Dalam International Journal of Trade Economics and Finance Vol. 5. No. 2, 2014.

Sam'ani. "Legalitas Wakaf Tunai : Studi atas Persepsi Ulama NU dan Muhammadiyah Kota Pekalongan". Tesis tidak diterbitkan. Semarang: IAIN Walisongo, 2003.

Quddus, Raihanatul. Persepsi Pesantren terhadap Wakaf Uang (Pesantren di Jabodetabek). Jakarta: Universitas Indonesia, 2009.

YPH PPD NW Pancor dan DPC PBB Kab. Lombok Timur. Mengenang Al Magfurullahu Maulanasyaikh Tuan Guru Kyai Haji Muhammad Zainuddin Abdul Madjid. Pancor, 2004.

Zainuddin, Muhammad. "Organisasi Nahdlatul Wathan. "http://zaikenawa.cc., diakses 30 Maret 2014. 